\title{
ASSESSING THE APPLICABILITY OF SERVQUAL MODEL ACROSS HEALTH CARE SETTINGS IN DEVELOPING COUNTRIES
}

by:

Ayu Chairina Laksmi")

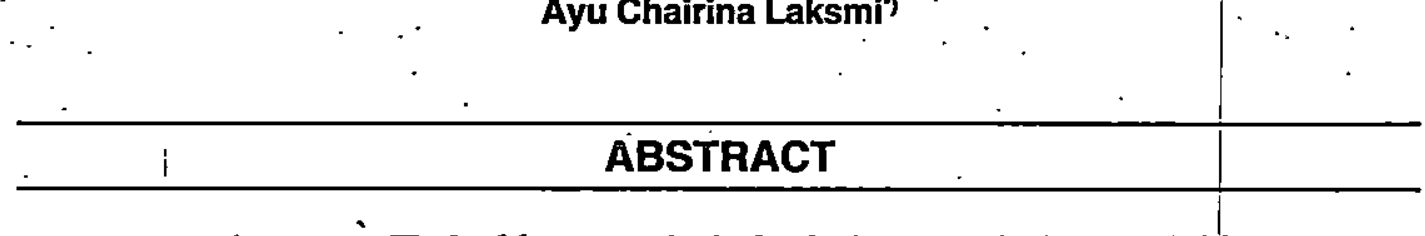

The health care service in developing countries is renowned for its poor service quality. However, interest in health care service quality in developing countries is relatively low compared to that in developed countries. It indicates that there are still unresolved problems about health care service quality measurement in developing countries. In developed countries, the SERVQUAL model is applied for measuring service quality in numerous health care settings. Hence, the purposes of this study are: (1) to assess the practicality of the SERVQUAL model in health care seroices in deoeloping countries; (2) to develop an improved SERVQUAL model for assessing health care service quality in developing countries; and (3) to investigate who should assess the health care service quality in developing countries. To achieve the purposes of this study, a qualitative research using a secondary case study is carried out. The credibility of the findings is established by reliability and validity check through making raw data used in this study accessible for the reader, writing field notes and also conducting triangulation. Initially, a modified SERVQUAL model is developed from the literature on the subject of health care service quality in developed country. Subsequently, the model is compared to the secondary data used in this study. The results from the data analysis demonstrate that the seroice dimensions of the SERVQUAL model need to be adjusted to the developing country context. It is also revealed that there are two other important dimensions that need to be incorporated in the SERVQUAL model, which are cost and country specific factor. Hence, the improved SERVQUAL model developed as one of the findings in this study, adds cost and country specific factor into its service dimensions. The final finding of this study demonstrates that both the health care providers and the patients in developing countries are the people who should assess the health care service quality

\section{INTRODUCTION}

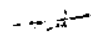

Parasuraman et al. $(1985,1988)$ propose an instrument called SERVQUAL to measure service quality. This instrument measures service quality by comparing customers' perception and expectation with service performance. One. industry that sees numerous applications of SERVQUAL is the health care

") Ayu Chairina Laksmi is Departrient of Accounting; Universitas Istam Indoriesia. 
industry (Asubonteng et al., 1996). At the moment, there are two approaches when measuring the health care service quality. The first approach is to observe it from the providers' or professionals' points of view, and the second approach is from the perspective of health care customer, namely the patients. However, there is more support given in the literature, to measure health care service quality from the patients' perceptions (Babakus and Mangold, 1992; Headley and Miller, 1993; McAlexander, 1994; Zifko-Baliga and Krampf, 1997; Newman et al., 1998; Merkouris, et al., 1999; Dabholkar et al., 2000; Andaleeb, 2001; Baltússen et al., 2002; Yellen et al., 2002; Gourdjii, et al., 2003; Kilbourne et al., 2004; Yildiz and Erdogmus, 2004; Kara et al., 2005; Ramsaran-Fowdar, 2005). Nonetheless, other authors (Walbridge and Delene, 1993; O'Connor, 1994; Licata et al., 1995; Lee et al., 2000) prefer to focus more on health care providers' or health care professionals' perceptions.

In developing countries, interest on health care service quality is relatively low compared to that in developed countries despite overwhelming published evidence of the low quality of care (Reerink and Sauerborn, 1996; Newman et al., 1998). The lack of interest suggests that there is no single agreement reached about health care service quality measurement and who should assess the service quality of health care in developing countries. Moreover, only a few studies in developing countries actually use a measurement model for measuring health care service quality.

This study attempts to fill the gap in the literature and to make a contribution to the body of knowledge by focusing on health care service quality in developing countries. The purposes of this study are:

1. To assess the practicality of the SERVQUAL model in health care in developing countries

2. To develop an improved SERVQUAL model for assessing health care service quality in developing countries

3. To investigate who should assess the health care service quality in developing countries

This study briefly discusses service quality which includes the debates on definition; the relationship between customer satisfaction and service quality; and measurement of service quality. The next section discusses service quality in the health care setting, followed by an overview of health care service quality in developing countries. Having reviewed the literature on service quality, particularly in health care settings, a modified SERVQUAL model can then be developed and tested against the secondary data used in this study. The research methodology elucidates how this study is going to be conducted, and subsequently followed by data analysis and triangulation. In the discussion section, the research questions proposed are answered and then followed by identification of any limitations of this study. Finally, a brief conclusion is provided to sum up the study and also to underpin the important points made in the study. 
Unlike good production, service delivery differs in the dimensions of intangibility, co-production, and simultaneous production and consumption (RaghavanGilbert et al., 1998). The quality management in service delivery can be quite problematic since senvice can neither be made, inspected, nor stored before production. One of probably the most influential and popular studies in service quality. and its measurement is the work by Parasuraman, et al. (1985). Three underlying themes proposed by Parasuraman et al. (1985) regarding service quality are: (1) service quality is more difficult for the consumer to evaluate than quality of goods, (2) service quality perceptions result from a comparison of consumer expectation with actual service performance, and (3) quality evaluations are not made solely on the outcome of service; they also involve evaluations of the process of service delivery.

\section{Causal Relationship between Customer Satisfaction and Service Quality}

The distinction between satisfaction and service quality is important because service providers need to know whether their objective should be to have consumers, who are satisfied with their performance, or to deliver the maximum level of perceived service quality (Cronin and Taylor, 1992). Zeithaml (in Parasuraman et al., 1988) defines perceived quality as the consumer's judgment about an entity's overall excellence or superiority. On the other hand, satisfaction is related closely to, but is not the same as, the customer's general attitude towards the service (Bitner, 1990). Parasuraman et al. (1985) propose that higher levels of perceived service quality result in increased consumer satisfaction. Thus, service quality is identified as an antecedent to customer satisfaction (Parasuraman et al., 1988; Woodside et al., 1989; Reidenbach and Sandifer-Smallwood, 1990; Babakus and Mangold, 1992; Cronin and Taylor; 1992; Anderson and Sullivan, 1993; Andaleeb, 2001; Kilbourne et al., 2004; Yildiz and Erdogmus, 2004; Kara et al., 2005).

On the contrary, other research evidence suggests that satisfaction is in fact an antecedent of service quality (Bitner, 1990; Bolton and Drew, 1991). In her empirical research, Bitner (1990) demonstrates that service encounter satisfaction is an input into the more general construct, perceived service quality (or attitude), which in turn leads to subsequent behaviours towards the service organisation. Correspondingly, Bolton and Drew (1991) hypothesize that perceived service quality is a function of a consumer's residual perception of the service quality from the prior period and consumer's level of dissatisfaction with the current level of service performance. This notion suggests that satisfaction is a distinct construct that mediates prior perceptions of service quality to form the current perception of service quality.

Apart from the two opposite stances on customer satisfaction and service quality relationship; some authors suggest that service quality and customer satisfaction are distinct and independent constructs; and each may not be 
antecedent to the other (McAlexander et al., 1994; Dabholkar, 2000; Sureshchandar et al., 2002).

\section{Measurement Debate}

Zeithaml et al. (1990) identify service quality from the customers ${ }^{i}$ perspective, which is the extent of discrepancy between customers' expectations or desires and their perceptions. This model, also known as the gap model, based on Oliver's disconfirmation model. In the disconfirmation theory, the perception of service quality is conceptualized as a comparison between the expected level of service and the actual service performance. According to Zeithaml et al. (1990), there are ten dimensions of service quality. These dimensions of service quality comprise tangibles, reliability, responsiveness, competence, courtesy, credibility, security, access, communication, and understanding the customer. The table 1 below explains the definition of SERVQUAL dimension (Zeithaml et al., 1990, p. 22).

Table 1: Definition of SERVQUAL Dimensions

\begin{tabular}{|l|l|}
\hline \multicolumn{1}{|c|}{ Dimension } & \multicolumn{1}{|c|}{ Definition } \\
\hline Tangibles & $\begin{array}{l}\text { Appearance of physical facilities, equipment, } \\
\text { personnel, and communication materials }\end{array}$ \\
\hline Reliability & $\begin{array}{l}\text { Ability to perform the promised service } \\
\text { dependably and accurately }\end{array}$ \\
\hline Responsiveness & $\begin{array}{l}\text { Willingness to help customers and provide prompt } \\
\text { service }\end{array}$ \\
\hline Competence & $\begin{array}{l}\text { Possession of the required skills and knowledge to } \\
\text { perform the service }\end{array}$ \\
\hline Courtesy & $\begin{array}{l}\text { Politeness, respect, consideration, and friendliness } \\
\text { of contact personnel }\end{array}$ \\
\hline Credibility & $\begin{array}{l}\text { Trustworthiness, believability, honesty of the } \\
\text { service provider }\end{array}$ \\
\hline Security & Freedom from danger, risk, or doubt \\
\hline Access & Approachability and ease of contact \\
\hline Communication & $\begin{array}{l}\text { Keeping customers informed in language they can } \\
\text { understand and listening to them }\end{array}$ \\
\hline $\begin{array}{l}\text { Understanding } \\
\text { the Customer }\end{array}$ & $\begin{array}{l}\text { Making the effort to know customers and their } \\
\text { needs }\end{array}$ \\
\hline
\end{tabular}

Furthermore, Zeithaml et al. (1990) find that the statistical analyses conducted in constructing the measurement of service quality - that is called SERVQUAL - shows a considerable correlation among items representing several of the original ten dimensions. In particular, the correlations suggest con- 
solidation of the last seven dimensions into two broader dimensions labeled assurance and empathy. Competence, courtesy, credibility, and security are now labeled assurance; while access, communication and understanding the customer are labeled empathy. The remaining dimensions - tangibles, reliability, and responsiveness - stay intact throughout the scale development and refinement process. Hence, although SERVQUAL has only five distinct dimensions, they capture facets of all the ten originally conceptualized dimensions. The new definition of five dimensions of SERVQUAL (Zeithaml et al., 1990, p. 26) can be found in table 2 below:

Table 2: SERVQUAL Five Dimensions

\begin{tabular}{|l|l|}
\hline \multicolumn{1}{|c|}{ Dimensions } & \multicolumn{1}{|c|}{ Definition } \\
\hline Tangibles & $\begin{array}{l}\text { Appearance of physical facilities, equipment, } \\
\text { personnel, and communication materials }\end{array}$ \\
\hline Reliability & $\begin{array}{l}\text { Ability to perform the promised service } \\
\text { dependably and accurately }\end{array}$ \\
\hline Responsiveness & $\begin{array}{l}\text { Willingness to help customers and provide } \\
\text { prompt service }\end{array}$ \\
\hline Assurance & $\begin{array}{l}\text { Knowledge and courtesy of employees and } \\
\text { their ability to convey trust and confidence }\end{array}$ \\
\hline Empathy & $\begin{array}{l}\text { Caring, individualized attention the firm } \\
\text { provides its customers }\end{array}$ \\
\hline
\end{tabular}

Currently, there are two views regarding senice quality measurement. One lends support to the SERVQUAL scale - developed by Parasuraman et al. (1985) - that uses the disconfirmation paradigm between performance and customers' expectation; while the other prefers to employ the SERVPERF scale developed by Cronin and Taylor (1992) - that is based solely on performance. Cronin and Taylor (1992) strongly argue that it is needless to measure customer expectations in service quality research, and there is little theoretical or empirical evidence which supports the relevance of the expectations-performance gap as the basis for measuring service quality. In response to those critics, Parasuraman et al. (1994) maintain that Cronin and Taylor (1992) appear to ignore prior work in the service quality literature that supports the disconfirmation of expectations conceptualization of service quality. However, although the stability of the dimensions of SERVQUAL is impressive (Carman, 1990), some.authors question its applicability across the senvice industries. Hence; there is a suggestion that there is a need to modify the SERVQUAL scale and wording according to the particular service industry being investigated. The next section discusses service quality in a specific senvice industry, i.e. health care and also its measurement using the SERVQUAL scale. 


\section{Research in Health Care Service Quality in Developing Countries}

There are a number of problems associated with research into health care provision and administration in developing countries (Joseph and Phillips, 1984). The first problem is demographic, manpower and financial data which are often out of date, not available or even not accurate. The second problem is the official statements that often do not match with the reality of any given situation, whether in terms of facility provision or in health levels. Joseph and Phillips (1984) explain that this problem is, to some extent, caused by a lack of data and the natural desire of government to represent their countries in a favourable light for some purposes, while maintaining a needy position for foreign aid. It is common to balance national and political pride against the need to secure overseas aid, especially in very expensive health service provision. Hence, sometimes the real situation may be even worse than what is depicted officially but at other times may actually be better.

Joseph and Phillips (1984) also notice problems with regard to pursuing basic utilization research in some developing countries, relating to language. and cultural problems as well as to a lack of trained research assistants, all of which lead to a lack of reliable published research. However, there are still some helpful and reliable studies into health care in developing countries. Examples of such studies are a study of patient satisfaction in hospitals in Bangladesh by Andaleeb (2001); a similar study in Mauritius by RamsaranFowdar (2005); outpatient satisfaction survey in Mozambique by Newman, et al. (1998); perception of service and needs in Orissa (India) by Ager and Pepper (2005); patient satisfaction in hospitals in Turkey by Yildiz and Erdogmus (2004); and health care programme evaluation tool in South Pacific countries by Raghavan-Gilbert et al. (1998). These studies will be discussed thoroughly in the data analysis section.

\section{III. ' RESEARCH QUESTIONS AND MODEL DEVELOPMENT}

\section{Research Questions.}

From the aforesaid discussion on measuring health care service quality using SERVQUAL and health care service quality in developing countries, three research questions can be formulated:

1. How practical is the SERVQUAL model for assessing health care service quality in developing countries?

2. What is an improved SERVQUAL model that can be applied for evaluating health care quality in developing countries?

3. Who should assess the health care service quality in developing countries?

\section{Model Development}

The modified SERVQUAL model used in this study is closely adapted from the SERVQUAL model developed by Parasuraman et al. $(1985,1988)$. 
The underlying principle, in adapting the SERVQUAL model, is its robustness when applied in à health care service context (Reidenbach and SandiferSmälwood, 1990; Cronin and Taylor, 1992; Babakus and Mangold, 1992; Headley and Miller, 1993). Nonetheless, the SERVQUAL model will need to be modified when applied in a specific service sector (Carman, 1990; Babakus and Boller, 1992; Lee et al., 2000). Hence, the modified SERVQUAL model used in this study is adapted to the health care service industry. The dimensions in the modified SERVQUAL model are taken from the study by Lee et al. (2000). The model consists of tangible and intangible dimensions. The definition of tangible dimension is identical to the original SERVQUAL dimensions, i.e. appearance of physical facilities, equipment, personnel, and communication materials. The intangible dimensions included in the model are: reliability, responsiveness, assurance, empathy, professionalism/skills, and core medical service. The following table, taken from Lee et al. $(2000$, p. 236) explains the definition of SERVQUAL attributes when applied to a health care setting.

Table 3: Service Quality Attributes

\begin{tabular}{|c|c|c|}
\hline Attribute & Definition & Authors \\
\hline Assurance & $\begin{array}{l}\text { Courtesy displayed by } \\
\text { physicians, nurses, or office staff } \\
\text { and their ability to inspire } \\
\text { patient trust and confidence }\end{array}$ & $\begin{array}{l}\text { Parasuraman, } \\
\text { Zeithaml, and } \\
\text { Berry, } 1988\end{array}$ \\
\hline Empathy & $\begin{array}{l}\text { Caring, individualized attention } \\
\text { provided to patients by } \\
\text { physicians and their staffs }\end{array}$ & $\begin{array}{l}\text { Parasuraman, } \\
\text { Zeithaml, and } \\
\text { Berry, } 1988\end{array}$ \\
\hline $\begin{array}{c}\text { Reliability } \\
\ddots \\
.\end{array}$ & $\begin{array}{l}\text { Ability to perform the expected } \\
\text { service dependably and } \\
\text { accurately }\end{array}$ & $\begin{array}{l}\text { Parasuraman, } \\
\text { Zeithaml, and } \\
\text { Berry, } 1988\end{array}$ \\
\hline $\begin{array}{c}\text { Responsiveness } \\
0\end{array}$ & $\begin{array}{l}\text { Willingness to provide prompt. } \\
\text { service }\end{array}$ & $\begin{array}{l}\text { Parasuraman, } \\
\text { Zeithaml, and } \\
\text { Berry, } 1988\end{array}$ \\
\hline Tangibles & $\begin{array}{l}\text { Physical facilities, equipment, } \\
\text { and appearance of contact } \\
\text { personnel }\end{array}$ & $\begin{array}{l}\text { Parasuraman, } \\
\text { Zeithaml, and } \\
\text { Berry, } 1988\end{array}$ \\
\hline $\begin{array}{l}\text { Core medical } \\
\text { service } \\
\cdots \\
\because \quad:\end{array}$ & $\begin{array}{l}\text { The central medical aspects of } \\
\text { the service: appropriateness, } \\
\text { effectiveness, and benefits to the } \\
\text { patient }\end{array}$ & $\therefore$ \\
\hline $\begin{array}{l}\text { Professionalism/ } \\
\text { skills }\end{array}$ & $\begin{array}{l}\text { Knowledge, technical expertise, } \\
\text { amount of training, and } \\
\text { experience }\end{array}$ & $\begin{array}{l}\text { Parasuraman, } \\
\text { Zeithaml, and } \\
\text { Berry, } 1988\end{array}$ \\
\hline
\end{tabular}


The core medical service and professionalism/skills/competence dimensions added to the modified SERVQUAL model used in this study are not included in the original SERVQUAL five dimensions scale developed by Parasuraman et al. $(1985,1988)$. The dimension of professionalism/skills/competence is found to be significant for assessing health care service quality by the patients (Haywood-Farmer and Stuart, 1988; Brown and Swartz, 1989; Walbridge and Delene, 1993; Lee et al., 2000; Ramsaran-Fowdar, 2005; Kilbourne et al., 2004). Likewise, core medical service is also deemed significant in shaping patients' perceptions of service quality (Walbridge and Delene, 1993; Bowers et al., 1994; Lee et al., 2000; Ramsaran-Fowdar, 2005). Moreover, Lee et al. (2000) maintain that the two dimensions are important when measuring the technical aspects of health care service.

\section{Model Reliability}

The reliability of the SERVQUAL model will be established by referring to the reliability test in previous studies. Babakus and Mangold (1992) are among the first to do a study that uses the SERVQUAL model in order to measure patient satisfaction. In their study, Babakus and Mangold (1992) also analyse the SERVQUAL in terms of the scale's reliability and items for each subscale are subjected to reliability assessment. The coefficient alpha values for the expectation subscales are $0.587,0.677,0.715,0.801$, and 0.495 for tangibles, reliability, responsiveness, assurance and empathy, respectively. The coefficient alpha values for perception subscales are $0.782,0.759,0.903,0.892$, and 0.874 for tangibles, reliability, responsiveness, assurance, and empathy respectively. Hair et al. (2006) explain that Cronbach's alpha is the most widely used reliability coefficient and it assesses the consistency of the entire scale. The generally agreed upon lower limit for Cronbach's alpha is 0.70 , though it may decrease to 0.60 in exploratory research (Hair et al., 2006).

Nonetheless, Babakus and Mangold (1992) use the cut-off value of 0.35 in assessing the coefficient alpha. Hence, it can be assumed that the subscales in the study conducted by Babakus and Mangold (1992) meet the required level of internal consistency. Furthermore, reliabilities for linear combinations of the five subscales are also computed to assess the overall internal consistency of the expectations and perceptions measures. The overall coefficient alpha val- ues are 0.897 and 0.964 for the expectations and perceptions scores, respectively. This demonstrates that both measures demonstrate desirable leveis of internal consistency at aggregate level (Babakus and Mangold, 1992).

In developing countries, the reliability examination of the SERVQUAL dimensions provides similar results to study in the developed countries. Andaleeb (2001) employs a modified SERVQUAL model with five dimensions adapted to the study setting in Bangladesh. The five dimensions used are responsiveness, assurance, communication, discipline, and baksheesh (extra money for due service). Each factor is assessed for reliability using coefficient alpha. The reliability coefficients for all of the dimensions are higher than the generally accepted value of 0,70 . Another study attempts to apply SERVQUAL model in a developing country is by Yildiz and Erdogmus (2004). In their study, Yildiz and Erdogmus (2004) attempt to apply a modified SERVQUAL scale in a health 
Ayu Chairina Laksmi: Assessing the Applicability of SERVQUAL Model...

care setting in Turkey. The seven factors included in their SERVQUAL model, are: nutritional care, physician care, nursing care, room atmosphere, procedure of incoming patients, room cleanliness, and other serving. They find that the coefficients alpha for the seven factors exceed the acceptable level of 0.70 recoimmended by literature.

Like Yildiz and Erdogmus (2004), Kara et al. (2005) also investigate the health care service quality in Turkey. However, Kara et al. (2005) use the original SERVQUALscales of tangibles; reliability, responsiveness, assurance, and empathy; plus an additional scale to measure courtesy. All the factors have coefficient alpha over or very close to the accepted value of 0.70 . To sum up, the discussion on SERVQUAL model reliability, both in developed and developing countries, demonstrates that the seven dimensions used in the model of this study can be accepted as being reliable for the research.

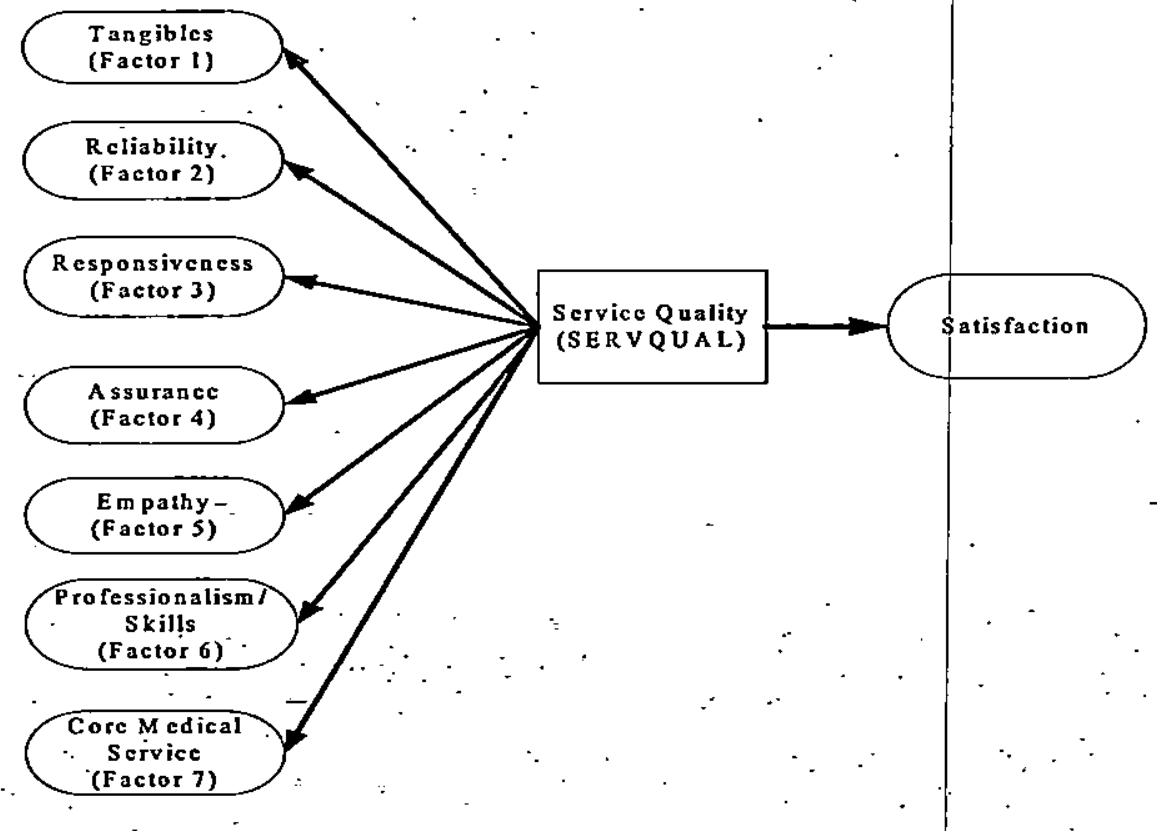

Figure 1: Modified SERVQUAL Model for Assessing Health Care Service Quality in Developing Countries

IV. Data Analysis

In this section, the data analysis focuses only on the main secondary data used in this study, which is the case study from developing countries. The main secondary data under investigation in this study is taken from the study. by Raghavan-Gilbert et al. (1998) and the title is 'Design and implementation of a program quality assessment tool: Three case studies of primary health services in developing countries', and is published in the International Journal of 
Quality and Reliability Management, 1998; 15(8/9). From their previous studies in developing countries, Raghavan-Gilbert et al. (1998) develop Program Quality Assessment Tool (PQAT). The PQAT is a practical management tool designed to generate information about program quality that middle managers can use directly to affect program performance, or indirectly to influence program policy makers.

According to Raghavan-Gilbert et al. (1998) the PQAT tries to reduce the quality gap between 'what is' and 'what should be', in program quality, by reducing the information gaps within the enabling system. This tool offers a feedback loop from the field, which guides the organization in establishing and conforming to country and project specific quality standards and requirements. Because it is managers who use the PQAT to evaluate the quality of the health service, the measurement of quality is given from the perspective of a service provider and not from service recipient's perspective. Raghavan-Gilbert et al. (1998) reinforce the fact that the PQAT is neither designed, nor empirically validated, as a research evaluation tool. Rather, the PQAT is designed for managers to use it and the theoretical and empirical validation in the PQAT is heuristic, following the qualitative tradition of grounded theory. The structure and measurement elements of the PQAT are derived from an underlying systems theory of quality embedded in the Program Quality Assessment model portrayed in Figure 2 below.

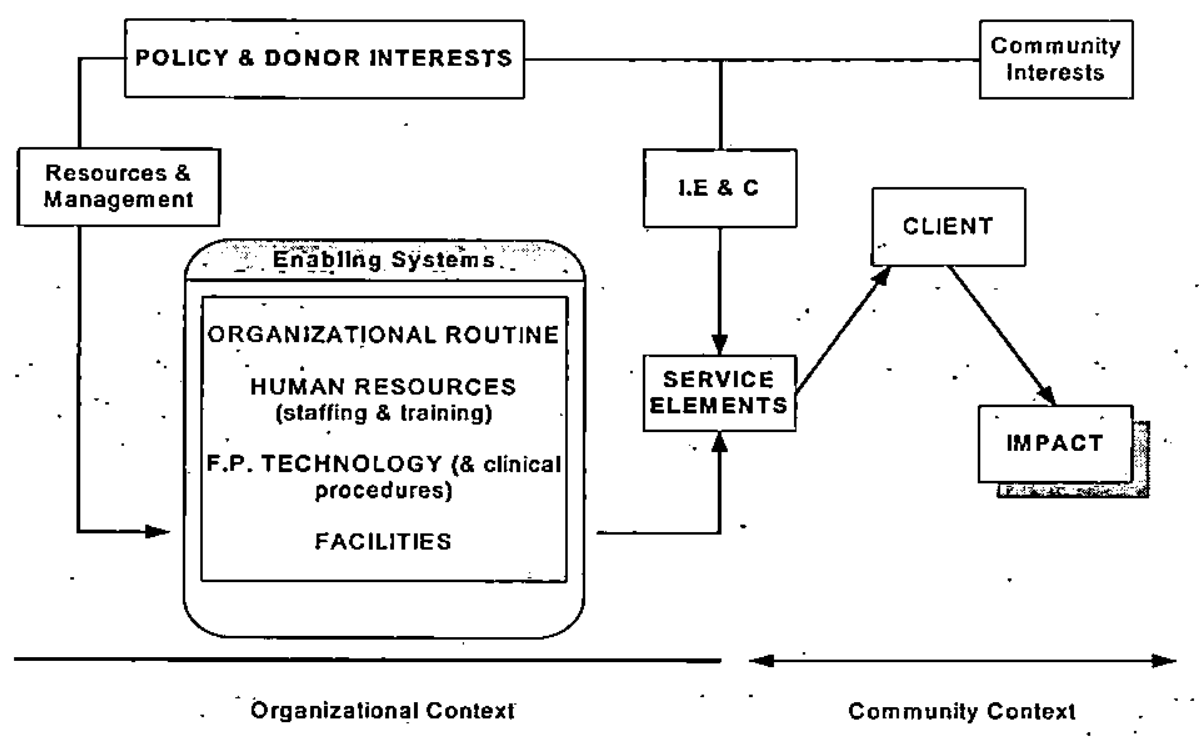

Figure 2: The Program Quality Assessment Model 
The above model shows that the central processes embedded in the enabling systems for organizational functions mediate inputs into the family planning program and outputs from service delivery activities. The model also demonstrates how the PQAT field evaluation tool and the standards direct the processes in the enabling systems. The PQAT uses 16 quality indicators to assess the quality of the health service: Raghavan-Gilbert et al. (1998) also explain that the PQAT has been used in Africa, the Middle East, and Asia. In their case study, Raghavan-Gilbert et al: (1998) observe the use of the PQAT in the farnily planning services in three island countries in the South Pacific. All of the three countries are former colonies and they are remote from the industrialized world. However, levels of social development in these countries are very different. In each country, the sites represent a mix of urban and rural clinic locations, and both government-run and independent clinic operations. The countries, used in this case study, are labeled country A, B, and C. Below is the analysis for each of the countries:

\section{Country A}

Among the three countries, country $A$ has the lowest level of economic and social progress since independence. Six clinics in country $A$ are used as samples in the observation, three of them are urban clinics and the rest are rural clinics. The case study reveals that the quality indicators in country $A$, that are not adequate, are: competence, safety, equipment, physical facility, access, standard and protocol, IEC (outreach), management information system (MIS), supervision, monitoring, client follow up and utilization.

\section{Country B}

To some extent, Country B is more developed than country A, partly because it is a popular destination for tourists. There are five clinics used as samples, two of them are urban clinics and three are rural clinics. The quality indicators in country $\mathrm{B}$, which are not adequate, are: competence, choice, safety, commodities, consumable, equipment, physical facility access, standard and protocols, IEC, MIS, supervision, monitoring, client follow-up and utilization. However, the utilization of the urbar clinics is high.

\section{Country C}

Country $C$ is larger than countries $A$ and $B$; and its infrastructure is also more highly developed. Country $C$ has higher performance in access, medical backup, consumable, equipment and generally better performance on skillsbased areas such as: competence, safety, supervision and MIS compared to countries A or B (Raghavan-Gilbert et al., 1998). There are ten clinics in country $C$ used as samples in the case study. Hence, the total number of clinics across the three countries is 21 clinics. To find out the quality level of indicators in the three countries a summary table is drawn. The table 4 below shows the number of clinics across countries $A, B$, and $C$ and the level of quality indicators. 
Table 4: Summary of Indicators Findings

\begin{tabular}{|l|c|c|c|}
\hline \multicolumn{1}{|c|}{ Indicators } & NO & N/A & AD \\
\hline Competence & & & 5 \\
\hline Choice & & & 16 \\
\hline Safety & & & 15 \\
\hline Medical backup & 1 & 1 & 19 \\
\hline Commodities & 1 & 1 & 10 \\
\hline Consumable & 1 & 1 & 11 \\
\hline Equipment & & & 10 \\
\hline Physical facility & & & 9 \\
\hline Access & & & 12 \\
\hline Standard and protocols & & & 2 \\
\hline IEC (outreach) & 1 & & 1 \\
\hline MIS & 1 &.$\cdot$ & 3 \\
\hline Supervision & & 1 & 6 \\
\hline Monitoring & & & 6 \\
\hline Client follow-up & & & 3 \\
\hline
\end{tabular}

$\mathrm{AD}$ : adequate quality only in this domain

N/A: not applicable because medical services not provided at this site

NO: many processes were not observable at this privately run clinic

From the above table, it can be seen that some of the indicators are found to be of inadequate quality in many clinics, yet some do not even exist. The highest number of clinics with adequate quality is found in the medical backup indicator, with 19 clinics out of 21 clinics across the three countries. Meanwhile, the least number of clinics with adequate quality is found in IEC (outreach), with only 1 clinic out of 21 clinics meeting the required standard. It can also be observed that most of the clinics have adequate quality in choice, safety, and medical backup. Yet, many clinics are lacking in commodities, consumable, equipment, access, competence, physical facility, standard and protocols, MIS, supervision, monitoring, and client follow-up.

In order to map the above quality indicators across the proposed modified SERVQUAL model developed in this study, the indicators need to be classified according to the six factors in the model in Figure 1, i.e. tangibles, reliability, responsiveness, assurance, empathy, professionalism/skills and core medical service. The following table shows the classification: 
Ayu Chairina Laksmi: Assessing the Applicability of SERVQUAL Model...

Table 5: Indicator Classification

\begin{tabular}{|l|c|}
\hline \multicolumn{1}{|c|}{ Indicator } & Factor \\
\hline Competence & Professionalism/skills \\
\hline Choice & Core medical service \\
\hline Safety & Assurance \\
\hline Medical backup & Assurance \\
\hline Commodities & Tangibles \\
\hline Consumable & Tangibles \\
\hline Equipment & Tangibles \\
\hline Physical facility & Tangibles \\
\hline Access & Reliability \\
\hline Standard and protocols & Reliability \\
\hline IEC (outreach) & Responsiveness \\
\hline MIS & Tangibles \\
\hline Supervision & Reliability \\
\hline Monitoring & Reliability \\
\hline Client follow-up & Responsiveness \\
\hline
\end{tabular}

From Table 4, the indicator of choice, safety, and medical back up are generally adequate across the clinics in countries A, B, and C. From Table 5 , the three adequate indicators can be classified into core medical services and assurance. Apart from those two factors, tangibles and reliability factors are also found to be adequate although the number of clinics with adequate indicators in tangibles and reliability is not many. The only SERVQUAL indicator that does not present at all in the PQAT is empathy. In addition to that, the indicator of management information system (MIS) and choice are quite difficult to be classified under the SERVQUAL dimensions. The decision made in this study, however, is to classify choice under core medical service dimen sion since the specification areas of choice are range available and method mix. For MIS the decision is to put it under the tangibles dimension because the specification areas for.MIS are records and forms and service statistics, which are clearly tangibles objects.

Concerning the third aim of this study, which is to investigate who should assess the health care service quality in developing countries, the study by Raghavan-Gilbert et al. (1998) appears to focus more on the perceptions of the health care providers. Raghavan-Gilbert et al. (1998) argue that general principles of quality measurement and management are supported by most programme managers; however, these are often not well understood in the field, at the operational, or in the headquarters levels of many programmes in less industrialised countries. Therefore, it can be concluded from the result of this data analysis that the health care providers in developing countries should assess the health care service quality they offer, in order to improve the quality of service, and thus to the well-being of the patients. 


\section{TRIANGULATION}

In this section two types of triangulation used in this study are presented. The first triangulation is data triangulation and the second is methodological triangulation.

\section{Data Triangulation Data 1}

The first data, used in data triangulation is taken from the study by Ager and Pepper (2005) with the title: 'Patterns of health service utilization and perceptions of needs and services in rural Orissa', and it is published in Health Policy and Planning, 2005;20(3). Orissa lies on the east coast of India and is one of the poorest and least developed states in India in terms of productivity, industrial output, employment, per capita income, social development and health status. Over $40 \%$ of its 36 million inhabitants live below the poverty line. More than $85 \%$ of the population in Orissa lives in rural areas, with $66 \%$ of all villages having a population of less than 500 . Health indicators, in the state, remain poor in spite of significant investment in the health sector in the last 15 years.

The interviews with respondents reveal factors that are affecting people's choice for health care providers. Reputation, cost and the ability to physically access care providers are three related factors in the patterns of choice of health care provider. Frequently superseding both cost and access, reputation is the factor most often quoted by villagers as influencing their choice of health care provider. Generally the villagers rely on the opinions and experiences of others when choosing where to get treatment. The reputation of the health care provider has a powerful influence on people's behaviour in terms of what obstacles they will tackle, how far they will travel and how much they are prepared to pay for their treatment.

The three factors mentioned above which are used by people in rural Orissa whien choosing health care provider, can be classified under the dimensions used in the proposed model in this study. The reputation of the health care provider is linked closely with competence and credibility; thus, it can be classified into the assurance dimension. Physical-access to the health care provider can be classified into the empathy dimension. As far as cost is concerned, this factor cannot be classified into the existing dimensions in the modified SERVQUAL model proposed in this study. Therefore, cost will be handled more appropriately when standing as a separate dimension. Ager and Pepper (2005) focus their study in the patients' perceptions regarding health care services in Orissa, India. Therefore, it can be assumed that in Orissa, India, the patients' perceptions are considered to be more important than the health care providers' perceptions.

\section{Data 2.}

The second data is taken from the study by Ramsaran-Fowdar and the title is 'Identifying health care quality attributes', and it is published in the Journal of Health and Human Services Administration, Winter 2004/Spring 2005; 
27(3/4): The exploratory study aims to comprehend the health care quality in the Maunitian context. Ramsaran-Fowdar (2005) argues that this study is important since there are no studies related to service quality of Mauritian physicians. The data collection method used is in-depth interviews with twelve patients within three weeks to investigate into the patients' needs and the benefits they hope to get from the service provided by private general practitioners (GPs).

In Maunitius, medical care is free in the public sector and is predominantly supplied by area health centers, district hospitals and regional/hospitals. In order to overcome the problem, the Mauritian govemment uses a staff retention strategy which allows public doctors to open private consultation practices. Consequently, there is a serious morale problem among hospital employees burdened with heavy workloads, poor compensation packages, low quality of work life, and poor leadership. All of these factors inevitably trigger the slow down of quality patient services delivery in the public sector. Hence, the general population perceives the public healthcare system negatively and many patients choose to go to private physicians.

Ramsaran-Fowdar (2005) compares the SERVQUAL dimensions, adapted from Parasuraman et al. (1985), with the results from the in-depth interviews. In grouping the respondents' answer into the service quality dimensions, he uses his own judgment and avoids using statistical processes, like factor analysis. The results demonstrate that the respondents interviewed add several additional attributes in each of five dimensions of service quality (tangibility, reliability, responsiveness, assurance and empathy). The study also reveals two additional quality dimensions, namely core medical outcomes and professionalism/skill/competence. Therefore, Ramsaran-Fowdar (2005) claims that dimensions in SERVQUAL cannot be replicated fully in health care services, since dimensions such as professionalism and core medical outcomes/services may come forward as equally critical when determining the attributes patients use to evaluate health care quality. It can also be observed that in his study, RamsaranFowdar (2005) only concentrates on the patients' perceptions of health care service quality. He argues that ensuring service quality is beneficial not only for patients but also for the health care providers as well, and that curtomer satisfaction and service quality remain critical issues in most service industries and are even more important in health care sector.

\section{Methodological Triangulation} Data 1

The first quantitative data analysed is obtained from the study by Newman et al. (1998). The title of the study is 'Satisfaction with outpatient health care services in Manica Province, Mozambique', and it is published in Health Policy and Planning, 1998, 13(2): 174-180: Newman et al. (1998) state that the objective of their study is to describe ambulatory health care services, determine the level of client satisfaction, and identify obstacles to the provision of care in a rural area of Mozambique.

The study is part of the effort to bring about better provision of health care in Mozambique, by conducting an exit survey of users of rural health posts and urban health centres in Manica Province, Mozambique: This exit survey 
collects data by using questionnaires at health clinics throughout Manica Province, Mozambique. The questionnaire is broadly divided into five areas focusing on demographic information, the primary reason for the visit, the nature of the interaction with the health care provider, satisfaction with the clinic visit, and problems with the clinic encounter on a particular day. Satisfaction is evaluated on a five point scale, from bad to very good and asked in a standardized mannier. to all interviewees. All responses represent patient reports, and are not corroborated with observational evidence.

The results of the study by Newman et al. (1998) demonstrate that the majority of people in Mozambique, using government health services in Manica province, are moderately satisfied with the quality of their health care quality. However, very few individuals are seen by physicians because, in all but four locations outside Chimio, they are not available. Therefore, the majority of individuals are seen by nurses, or by orderlies in many cases. Those who believe that they have been seen by an orderly are significantly more likely to be dissatisfied with the service than those who have been seen by a nurse. There is also a significant association between satisfaction score and waiting time, with longer waiting times associated with lower satisfaction scores. Another significant association is between satisfaction and confidence in the provider and perceived respect from the provider. Among the 879 respondents, the most frequently spotted problems, affecting utilization on the day of the clinic visit, are difficulty in getting to the clinic (transportation, distance), long waiting times in the clinic and lack of a physical examination. A number of respondents also have a complaint about medication, as some of them are not receiving some or all of their medication, and others claim that they have been overcharged. Overall, $60 \%$ of the respondents have at least one response to an open question regarding the health care system in general, which included difficulties in the dispensing of medication, lack of adequate personnel to staff the clinics, lack of transportation, and clinic hours and delays.

It can be concluded from the study by Newman et al. (1998) that patient satisfaction with health care services can be associated with professionalism/ skills of the provider, waiting time, confidence of the provider, and perceived respect from the provider. These factors can be classified into the modified SERVQUAL dimensions used in the proposed model of health service quality. The waiting time can be classified into the responsiveness category, since the definition of responsiveness is willingness to provide prompt service. Confidence of the provider can be categorized into the assurance dimension as assurance is courtesy displayed by physicians, nurses, or office staff and their ability to inspire patient trust and confidence. Similarly, perceived respect from the provider can also be categorized under the assurance dimension. The study by Newman et al. (1998) also demonstrates that the patients' perceptions are invaluable when measuring health care service quality. They argue that if health programmes are to succeed in resource-poor countries, it is crucial to elicit the opinions of.local people, in addition to their degree of satisfaction with available health services. 


\section{Data 2}

The second data used in the methodological triangulation is the study by Baltussen et al. (2002). The title of the study is 'Perceived quality of care of primary health care services in Burkina Faso., and it is published in Health Policy and Planning, 2002, 17(1). The study investigates the measurement of perceived quality of care of primary health care services in the health district of Nouna, Burkina Faso:Previous qualitative research into the perceived quality of care, in the same district, shows that patients are not satisfied with the health care services offered. In their study, Baltussen et al. (2002) employ the scale developed and validated by Haddad et al. (in Baltussen et al., 2002). However, the scale is adjusted for the specific context of Burkina Faso, and includes individual perceptions of health personnel practices and conduct, adequacy of resources and services, health care delivery, and financial and physical accessibility of care.

According to Baltussen et al. (2002), the purpose of their study is to inform policy-makers about the strengths and weaknesses of the quality of govemment primary health care services, as perceived by users, which can help identify starting points to improve the quality of health care. Furthermore, the study also aims to contribute to the further development of an analytical framework for the measurement of the perceived quality of care. The data in the study are collected from 1081 visitors to one urban hospital and 10 rural health care centres in the district of Nouna, in nort-west Burkina Faso. The rural health centres offer basic outpatient services and include a dispensary and maternity unit, staffed by a certified nurse and a trained midwife. The instrument used to collect the data is questionnaires. The study consists of 20 focus groups in five villages and it seeks to identify criteria that the lay people use to assess quality : of care.

From the factor analysis, Baltussen et al. (2002) discover four factors, used by the respondents, in assessing quality of care. The four factors are: health personnel practices and conduct; adequacy of resources and services, health care delivery, and financial and physical accessibility of care. The items under the four factors are presented on the Table 6 below. Respondents in various health centers (inclüding the urban hospital) are relatively negative in response to items related to health personnel practices and conduct. Nevertheless, health planners hardly ever pay attention to this problem and appear to focus more on the technical aspects of quality. The overall positive attitude, of the respondents, to health care delivery seems to conflict with earlier research in the same district, which has shown inadequate physical examination, diagnosis and prescription by personnel. It appears that respondents do not notice poor compliance rates with respect to these issues. The second factor, which is the quality of adequacy of resources and services, is also judged by the respondents as relatively poor. The absence of drugs which can be provided for all diseases at the centers at the time of visits is especially criticized by the respondents. Respondents also think that the financial and physical accessibility of care is relatively poorly. The high cost of care and the lack of access to credit are the factors that, in particular, considerably hampered the perceived quality of care. 
The items included in health personnel and conduct can be classified into the SERVQUAL dimensions of assurance and empathy. The adequacy of resources and services can be classified into tangibles, since they all can be observed physically. Health care delivery can be categorized into core medical services; and financial and physical accessibility of care can be included under the empathy dimension. The cost of care, as with the result of study by Ager and Pepper (2005), should be categorized as a separate dimension. Similar to other previous studies in developing countries, the patients' perceptions of health care service quality is also considered to be important in the study by Baltussen et al. (2002). They argue that patients' views are being given more and more significance in policy-making. Therefore, it is critical to recognize populations' perceptions of quality of care when developing measures to increase the utilization of primary health care services.

\section{Data 3}

The next data is taken from the study by Yildiz and Erdogmus (2004). The title of the study is 'Measuring patient satisfaction of the quality of health care: A study of hospitals in Turkey', and it is published in Journal of.Medical Systems, 28(6), December 2004. The health care system in Turkey is quite complex and under it, patients are not allowed to choose their doctors and hospitals. If the patients would like to receive care, they must go to the Social Security System's hospitals, which are funded by social insurance institutions, the government employees' retirement fund, and bag-kur. The grounds of this system are institutional organisations, law, and civil politics in Turkey.

According to Yildiz and Erdogmus (2004), health care competition in Turkey does not exist yet, since public hospitals in Turkey are not established to make money and the private sector is still trying to improve its quality, like other health private sectors are in most of the developing countries. However, the quality has notbeen improved, since increasing demand has not been met, day by-day, due to population increase. Moreover, public hospitals have serious financial and quality problems. To resolve the problem, the government starts to improve the quality of health care by fostering efforts in health care quality improvement. Health care managers must put less emphasis on bureaucracy and develop new strategies with quality as the first priority. One of the strategies is perhaps to prioritize patient satisfaction. However, it is known that the patient satisfaction is not generally the aim of research in developing countries, such as Turkey.

Yildiz and Erdogmus (2004) employ the SERVQUAL scale for determining patient satisfaction with nursing care. They argue that the previous studies .about health care evaluation assume that improved instruments for developed countries are also valid for Turkey. Nonetheless, the patient satisfaction instrument varies with respect to time and culture. Seven variables, related to patient satisfaction, are investigated in the study. The seven variables and items included in each variable are listed below:

The seven abovementioned factors, with very satisfactory measurement properties, represent patient-centred service quality indicators in the hospital setting; their use in evaluating hospital services should help health care work- 
ers to offer better care to the patients, who are often neglected (Yildiz and Erdogmus, 2004). The result of the study demonstrates that the physician care, nursing care, and nutritional care have more important roles in determining patient satisfaction. Additionally, the procedures used with incoming patients, room cleanliness, room atmosphere, and other service provision are also deemed to be important. By classifying the items under each factor according to the proposed SERVQUAL model in this study (Figure 1), it can be demonstrated that assurance, empathy, tangibles, reliability, responsiveness, - professionalism/skills are deemed to be important by patients in Turkey. The only dimension that does not appear in the study by Yildiz and Erdogmus (2004) is core medical service. Furthermore, it can also be concluded that the patients' perceptions of health care service quality is also significant in the study by Yildiz and Erdogmus (2004). They argue that patient satisfaction is an important measure of service quality in health care system and it has been an integral and critical part of quality health care.

\section{Data 4}

The next data is taken from the study by Andaleeb (2001) with the title of 'Service quality perceptions and patient satisfaction: A study of hospitals in developing country', which is published in Social Science \& Medicine, 2001, 52. The study addresses two major research objectives: 1) to determine what constitutes service quality in the context of hospitals in Bangladesh; 2) to assess how key service quality dimensions relate to an important measure of performance - patient satisfaction. The study also attempts to formulate a strategic vision to enable hospitals and the overall health care system to deliver higher levels of patient satisfaction.

There are three major challenges facing the health care delivery system in Bangladesh: improving quality, increasing access, and reducing costs. Although all three of them are important, there is growing evidence that the perceived quality of health care services influences patient behaviours more than access and cost do (Andaleeb, 2001). Quality problems are also pervasive in Bangladesh, where the government increases allocations of money to improve health care. Private health care has also been encouraged since 1982, leading to the establishment of 346 private hospitals in the country by June 1996. Nevertheless, there is evidence that people in Bangladesh, who can afford it, are obtaining health care services in neighbouring countries, regardless of the high costs and inconveniences of going abroad. Hence, they are conveying a strong message: they want quality services.

Andaleeb (2001) uses secondary research, qualitative interview and questionnaires as data gathering methods in his research. Further, Andaleeb (2001) argues that the Bangladesh context of the study suggests the need to consider additional factors when establishing service quality criteria and their measures. Based on the qualitative interview, Andaleeb (2001) identifies five factors used by the patients in measuring service quality. The five factors are: responsiveness, assurance, communication, discipline, and baksheesh. Baksheesh and discipline are the factors that are specific to the Bangladesh context. Baksheesh is extra money for a due seivice and the need for baksheesh may become so 
embedded that its harassment (or facilitation) value, in the provision of the health care service, cannot be overlooked. In Bangladesh, the patients' fates may be determined by their ability to give baksheesh. Discipline, or lack of it, is another aspect of service that is commonly found to be deteriorating in Bangladesh and that quickly diminishes overall satisfaction with the health care service. The tangibles dimension, such as the appearance of physical facilities, equipment, personnel and communication material (combined. with two.additional items during factor analysis), portrays the extent of discipline that exists in Bangladesh's hospital environment. Poor discipline is common to many services and is revealed in the failure to perform duties by employees.

The results of the study show that discipline, as an extension of the tangibles dimension, has the greatest influence on customer satisfaction and assurance comes second. According to Andaleeb (2001), in an environment where the professional demeanour and performance of the hospital staff, especially doctors, are often criticized, it is unsurprising that patients are more satisfied when they feel more assured of their health outcomes. Moreover, there is evidence that, for services with credence properties, assurance has an important role in patient satisfaction. Hence, the finding is corroborated, especially by the fact that other studies suggest the similarity of needs between patients in developed and developing countries (Andaleeb, 2001).

Andaleeb (2001) finds that, apart from discipline and assurance, responsiveness and communication also have a significant impact on patient satisfaction. The finding of the study also reveals that, although baksheesh is found to be significant, it has the least impact on patient satisfaction. Andaleeb (2001) concludes that the low impact of baksheesh supports the main thesis of his study - that quality, through assurance and discipline, is more important than cost and access as reflected in baksheesh. The five factors identified by Andaleeb (2001) can be mapped into the modified SERVQUAL model developed in this study. However, the communication and discipline factor cannot be classified into sepärate factors. According to Zeithaml et al. (1990), communication is classified into the empathy dimension, hence the communication factor found by Andaleeb (2001) will be classified under the empathy dimension in the modified SERVQUAL model in this study (Figure 1). As for discipline, Andaleeb (2001) explains that it is an extension of tangibles factor, therefore it can be classified under the tangibles factor in the modified.SERVQUAL model in Figure 1. Baksheesh, on the other hand, cannot be classified under the modified SERVQUAL model, since it is applicable only to health care settings in Bangladesh. As for the issue of who should assess the quality of health care service, Andaleeb (2001) strongly argues that patients' voice must begin to play a greater role in the design of health are service delivery processes in the developing countries.

\section{DISCUSSION AND LIMITATIONS}

The result from the analysis of the study by Raghavan-Gilbert et al. (1998). demonstrates that not all of SERVQUAL dimensions are present when the health care providers in developing countries evaluate their service quality. One 
dimension that does not emerge is the empathy dimension. Moreover, RaghavanGilbert et al. (1998) also find other dimensions that originally are not included in SERVQUAL, such as professionalism/skill and core medical service. The summary of data analysis and triangulation results is presented in Table 8 below. In this table, the findings are classified into the original five SERVQUAL dimensions, as suggested by Parasuraman et al. $(1985,1988)$. Additionally, other dimensions not originally included in those five SERVQUAL dimensions, are classified separately.

Table 6: Summary of Data Analysis and Triangulation

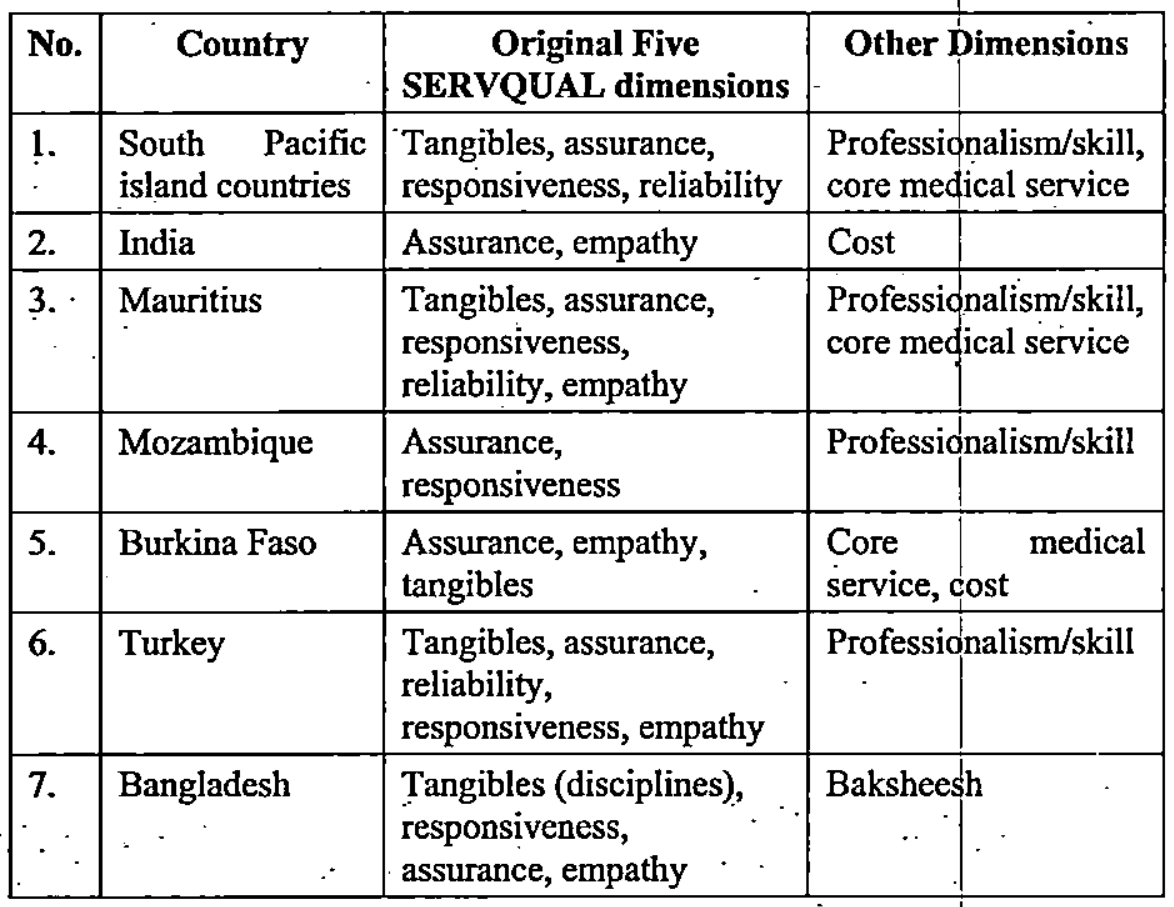

The above table also reveals that for most of the countries under investigation, professionalism/skill and core medical service are important for the patients when they assess the health care service quality they have received. These findings also lend support to the inclusion of professionalism/skill and core medical service dimension in the modified SERVQUAL model developed in this study (Figure 1). The triangulation also demonstrates that, in evaluating health care quality using the SERVQUAL model, the model's dimensions needs to be adapted to the developing country's context. For instance, the concept of baksheesh, in Bangladesh, is specific only to that country and does not apply. to other developing countries.

Another factor that is considered to be important for the patients in developing countries is the cost of health care. The triangulation demonstrates that, in Burkina Faso and in India, cost of care plays an important role in shaping the patients' perception of service quality. This finding is in line with the finding of the study by Andaleeb (1998) who investigates determinants of customer satis- 
faction with hospitals in the United States of America. However, the context of Andaleeb's study is health care service quality in a developed country. By contrast, a study by. Rose et al. (2004) that examines the hospital service quality in Malaysia reveals that cost dimension is insignificant in influencing Malaysian patients' perception of service quality. Rose et al. (2004) also explain that cost could be perceived by the patients as not being an "attractive" or a "one-dimensional" quality attribute. Rather, cost could be perceived as a "must be" attribute that patients take for granted when such a need is fulfilled. Nevertheless, quality in services is subjective, defined by individual customers. Thus, the mixed finding regarding cost of care should be investigated further in future research, especially in the developing countries context.

The data analysis and triangulation also demonstrate that the studies of health care senvice quality in developing countries focus on both the patients' perceptions and on the health care providers' perceptions. Thus, the patients' and the health care providers' views regarding health care service quality in developing countries are equally important. It can also be concluded that, in evaluating the quality of health care service, the patients in developing countries use the five SERVQUAL dimensions of tangibles, assurance, reliability, responsiveness, empathy and also professionalism/skill and core medical service. Apart from those dimensions, it appears that the patients also use other factors, such as cost and specific country factor (such as baksheesh in Bangladesh), in assessing the quality of the health care service. Hence, the findings suggest that the proposed modified SERVQUAL model can be improved by accommodating other dimensions considered important for the patients in developing countries. The Figure 4 below presents the improved modified SERVQUAL model that is developed as the finding of this study.

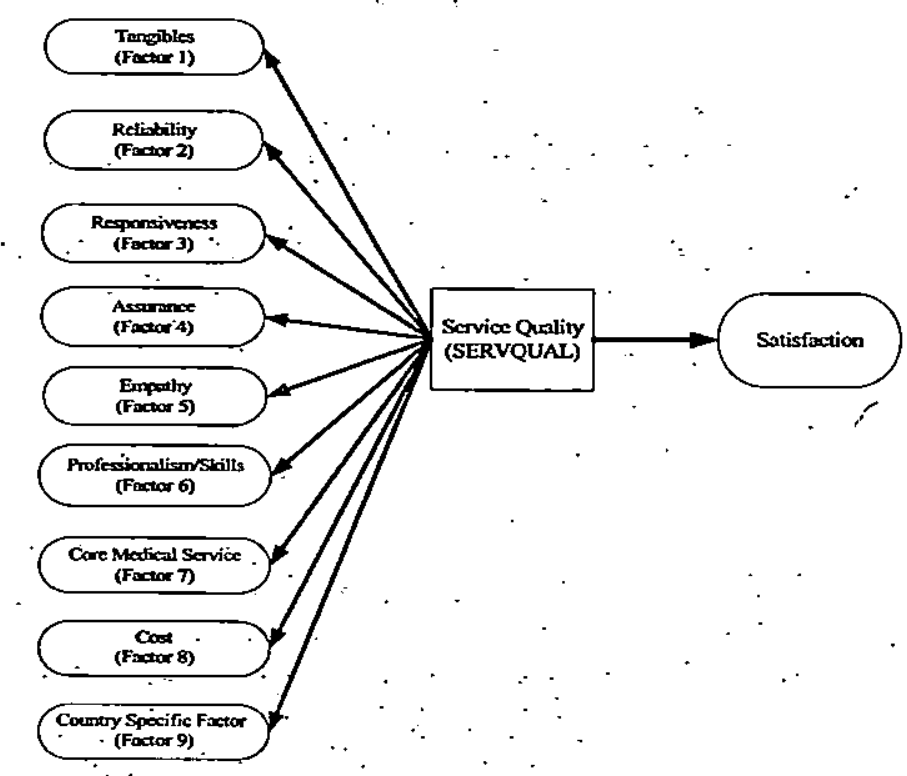

Figure 4. An Improved SERVQUAL Model for Assessing Health Care Service Quality in Developing Countries 
Ayu Chairina Laksmi: Assessing the Applicability of SERVQUAL Model...

Due to time and financial constraints, the data used in this study are taken from secondary data sources. Hence, the findings in this study may not be as accurate as findings from other studies, which have used primary data when investigating the service quality of health care in developing countries. Another limitation of this study is the use of the author's own judgment when classifying service quality. factors obtained from secondary data to the -SERVQUAL dimensions proposed in Figure 1. For that reason, the findings of this study cannot be generalized to other health care settings in developing countries.

The aim of this study is to fill in the gap in the literature and also to make a contribution to the body of knowledge by addressing three main objectives: 1) to assess the practicality of the SERVQUAL model in health care in developing countries; 2) to develop an improved SERVQUAL model for assessing health care service quality in developing countries; 3 ) to investigate who should assess the health care service quality in developing countries. The research approach in this study is a qualitative approach, with case study as a research strategy. Due to time and budget constraints, however, this study only uses secondary data.

Several conclusions emerge from the data analysis. Firstly, the SERVQUAL model is practical to be used for assessing the health care service quality in developing countries, although the model needs to be modified. Secondly, the study also finds that there are two additional factors used by the patients, in developing countries, to evaluate health care service quality. Those two factors are cost and country specific factors and, they should be added to the improved SERVQUAL model for assessing health care in developing countries. The third conclusion that can be drawn from the study is that both the patients and the health care providers in developing countries are the people who should assess the service quality of health care:

To finish, service quality measurement efforts in developing countries should be supported by national policies which provide an institutional framework. Thus, the need for strong leadership in developing countries to support the efforts is critical. It is also highly recommended to involve both the patients and the health care providers, in establishing the health care service quality standard in developing countries. The academic community is also encouraged to conduct further research to find the most suitable model for measuring heaith care service quality in developing countries. 


\section{REFERENCES}

Ager, A. and Pepper, K. (2005). Pattems of health service utilization and perceptions of needs and services in rural Orissa. Health Policy and Planning [Online], 20(3), pp. 176-184: Available:ABI/INFORM Global [Accessed 25 December 2006].

Andaleeb, S. S. (1998). Determinants of customer satisfaction with hospitals: A managerial model. Intemational Joumal of Health Care Quality Assurance [Online], 11(6), pp. 181-187. Available: Business Source Premier. [Accessed 24 March 2007].

Andaleeb, S. S. (2001). Service quality perceptions and patient satisfaction: A study of hospital in developing country. Social Science and Medicine [Online], 52, pp. 1359-1370. Available: ScienceDirect. Journals [Accessed 21 November 2006].

Anderson; E. W. and Sullivan, M. W. (1993). The antecederits and consequences of customer satisfaction for firms. Marketing Science [Online], 12(2), pp. 125-143. Available: Business Source Premier. [Accessed 20 November 2006].

Babakus, E. and Mangold, W. G (1992). Adapting the SERVQUAL scale to hospital services: An empirical investigation. Health Services Research [Online], 26(6), pp. 767-786. Available: PubMed Central. [Accessed 30 October 2006].

Babakus, E. and Boller, G. W. (1992). An empirical assessment of the SERVQUAL scale. Joumal of Business Research [Online], 24, pp. 253-268. Available: ScienceDirect Journals. [Accessed 30 October 2006].

Baltussen, R. M. P. M., Ye, Y., Haddad, S., and Sauerborn, R. S. (2002). Perceived service quality of care of primary health care services in Burkina Faso. Health Policy and Planning [Online], 17(1), pp. 42-48. Available: ABI/INFORM Global. [Accessed 25 December 2006].

Bitner, M. J: (1990). Evaluating service encounters: The effects of physical surroundings and employee responses. Joumal of Marketing [Online], 54(April), pp.69-82. Available: Business Source Premier. [Accessed 20 November 2006].

Bolton, R. N. and Drew, J. H. (1991). A multistage model of customers' assessment of service quality and value. Joumal of Consumer Research [Online], 17(March), pp. 375-384. Available: Business Source Premier. [Accessed 20 November 2006]. 
Ayu Chairina Laksmi: Assessing the Applicability of SERVQUAL Model...

Bowers, M. R., Swan, J..E., and Koehler, W. F. (1994). What attributes determine quality and satisfaction with health care delivery? Health Care Management Review [Online], 19(4), pp. 49-55. Available: ABI/ INFORM Global [Accessed 30 October 2006].

Brown, S. W. and Swartz, T. A. (1989). A gap analysis of professional service quality. Joumal of Marketing [Online], 53(April), pp, 92-98. Available: Business Source Premier. [Accessed 20 November 2006].

Carman, J. M. (1990). Consumer perceptions of service quality: An assessment of the SERVQUAL dimensions. Joumal of Retailing [Online], 66(1), pp. 33-55. Available: Business Source Premier. [Accessed 26 December 2005].

Cronin, J. J, Jr., and Taylor, S. A. (1992). Measuring service quality: A reexamination and extension. Joumal of Marketing [Online], 56, pp. 55-68. Avàilable: Business Source Premier. [Accessed 26 December 2005].

Dabholkar, P. A., Shepherd, C. D., and Thorpe, D.I. (2000). A comprehensive framework for service quality: An investigation of critical conceptual and measurement issues through a longitudinal study. Joumal of Retailing[Online], 76(2), pp. 139-173. Available: Business Source Premier. [Accessed 20 November 2006].

Gourdji, I., McVey, L., and Loiselle C. (2003). Patients' satisfaction and importance ratings of quality in an outpatient oncology center. Joumal of Nursing Care Quality [Online], 18(1), pp. 43-55. Available: Academic Search Elite. [Accessed 22 January 2007].

Hair, J. F., Black, W. C., Babin, B. J., Anderson, R. E., and Tatham, R. L. (2006). Multivariate data analysis (6th ed.). Upper Saddle Rivei, NJ: Pearson Prentice Hall.

Headley, D. E. and Miller, S. J. (1993). Measuring service quality and its relationship to future consumer behavior. Joumal of Health Care Marketing [Online], 13(4), pp. 32-41. Available: Business Source Premier. [Accessed 24 December 2005].

Joseph, A. E. and Phillips, D. R. (1984). Accessibility and utilization: Geographical perspectives on health care delivery. New York: Harper \& Row.

Kara, A:, Lonial, S., Tarim, M., and Zaim, S. (2005). A paradox of service quality. in Turkey: The seemingly contradictory relative importance of. tangible and intangible determinants of service quality. European Business Review [Öline], 17.(1), pp. 5-20. Available:ABl/INFORM Global. [ Accessed 20 December 2006]. 
Kilboume, W. E., Duffy, J. A., Duffy, M., and Giarchi, G. (2004). The applicability of SERVQUAL in cross-national measurements of health care quality. Joumal of Services Marketing [Online], 18(6/7), pp. 524-533. Available: ABI/INFORM Global. [Äccessed 25 October 2006].

Kirk, J. and Miller, M. L. (1986). Reliability and validity in qualitative research. Newbury Park, CA: Sage Publications.

Lee, H., Delene, L. M., Bunda, M. A., and Kim, C. (2000). Methods of measuring health-care service quality. Journal of Business Research [Online], 48, pp. 233-246. Available: ScienceDirect Elsevier Science Journals. [Accessed 24 December 2005].

Licata, J. W., Mowen, J. C., and Chakraborty, G. (1995). Diagnosing perceived quality in the medical service channel. Joumal of Health Care Marketing[Online], 15(4), pp. 42-49. Available: Business Source Premier. [Accessed 24 December 2005].

- McAlexander, J. H., Kaldenberg, D. O., and Koenig, H. F. (1994). Service quality measurement: Examination of dental practices sheds more light on the relationships between service quality, satisfaction, and purchase intentions in a health care setting. Journal of Health Care Marketing [Online], 14(3), pp. 34-39. Available: Business Source Premier. [Accessed 19 October 2006].

Merkouris, A., Ifantopoulos, J., Lanara, V., and Lemonidou, C. (1999). Patient satisfaction: A key concept for evaluating and improving nursing services. Joumal of Nursing Management [Online], 17(1), pp. 19-28. Available: Blackwell-Synergy. [Accessed 22 January 2007].

Newman, R. D., Gloyd, S., Nyangezi, J. M., Machobo F., and Muiser, J. (1998). Satisfaction with outpatient health care senvices in Manica Province, Mozambique. Health Policy and Planning [Online], 13(2), pp. 174-180. Available: Highwire Press (Free Joumals). [Accessed 30 January 2007].

Parasuraman,.A., Zeithaml, V. A., and Berry, L. L. (1985). A conceptual model of service quality and its implications for future research. Journal of Marketing [Online], 49(4), pp.41-50. Available: Business Source Premier. [Accessed 24 December 2005].

Parasuraman, A., Zeithaml, V. A., and Berry, L. L. (1988). SERVQUAL: A multiple-item scale for measuring consumer perception of senice quality. Joumal of Retailing [Online], 64(1), pp. 12-40. Available: Business Source Premier. [Accessed 24 December 2005].

Ramsaran-Fowdar, R. R. (2004). Identifying health care quality attributes. Journal of Health and Human Services Administration [Online], 27(3/ 
Ayu Chairina Laksmi: Assessing the Applicability of SERVQUAL Model...

4), pp. 428-443. Available: ABI/INFORM Global. [Accessed 24 December 2006].

Raghavan-Gilbert, P., Phillips, D., and Gilbert, A. L. (1998). Design and implementation of a program quality assessment tool: Three case studies of primary health services in developing countries. The International Joumal of Quality and Reliability Management [Online], 15(8/9), pp. 791-811: Available:ABIINFORM Global [Accessed 21 November 2006].

Reidenbach, R. E., and Sandifer-Smallwood, B. (1990). Exploring perceptions of hospital operations by a modified SERVQUAL approach. Journal of Health Care Marketing [Online], 10(4), pp. 47-55] Available: AB!/ INFORM Global. [Accessed 24 December 2005].

Reerink, I. H. and Sauerborn, R. (1996). Quality of primary health care in developing countries: Recent experiences and future directions. International Joumal for Quality in Health Care [Online], 8(2), pp. 131-139. Available: Oxford Journals Online. [Accessed 28 November 2006].

Rose, R. C., Uli, J., Abdul, M., and Ng, K. L. (2004). Hospital service quality: A managerial challenge. Intemational Joumal of Health Care Quality Assurance [Online], 17(2/3), pp. 146-159. Available: ABI/INFORM Global. [Accessed 24 March 2007].

Sureshchandar, G. S., Rajendran, C., and Anantharaman, R. N. (2002). The relationship between service quality and customer satisfaction - a factor specific approach. The Joumal of Services Marketing [Online], 16(4), pp. 363-379. Available:ABI/INFORM Global. [Accessed 20 November 2006].

Walbridge, S. W., and Delene, L. M. (1993). Measuring physician attitudes of service quality. Joumal of Health Care Marketing [Online], 13(1), pp. 6-15. Available: Business Source Premier. [Accessed 20 November 2006].

Woodside, A. G., Frey, L. L., and Daly, R. T. (1989). Linking service quality, customer satisfaction, and behavioral intention. Joumal of Health Care Marketing[Online], 9(4), pp.5-17. Available: Business Source Premier. [Accessed 30 October 2006].

Yellen, E., Davis, G C., and Ricard, R. (2002). The measurement of patient satisfaction. Joumal of Nursing Care Quality [Online], 16(4), pp. 2329. Available: Academic Search Elite. [Accessed.22 January 2007].

Yildiz, Z. and Erdogmus, S. (2004). Measuring patient satisfaction of the quality of health care: A study of hospitals in Turkey. Journal of Medical Systems [Online], 28(6), pp. 581-589. Available: SpringerLink Contemporary. [Accessed 23 January 2007]. 
Zeithaml, V. A., Parasuraman; A., and Berry, L. L. (1990). Delivering quality service: Balancing customer perceptions and expectations. New York: The Free Press.

Zifko-Baliga, G. M. and Krampf, R. F. (1997). Managing perceptions of hospital quality. Marketing Health Services [Online], 17(1), pp. 28-35. Available: ABI/INFORM Global. [Accessed 24 December 2005]. 